\title{
O PORTADOR DE TRANSTORNO MENTAL E A VIDA EM FAMÍLIAa
}

\author{
Mental health patients and family life \\ El portador de trastorno mental y la vida en familia
}

\section{RESUMO}

0 objetivo geral deste estudo foi revelar, na ótica familiar, a participação do portador de transtorno mental na vida em família. Pesquisa de abordagem qualitativa, realizada no período de março a maio de 2010. Os 14 colaboradores pertencem a onze famílias de portadores de transtornos mentais residentes no município de Maringá-Pr. Foi utilizada a história oral temática como técnica de coleta dos dados. Para análise dos dados utilizou-se a técnica de análise de conteúdo temática. Os resultados demonstram que, em relação à participação e decisões em família, ainda há dificuldades neste aspecto. Quanto à participação nas tarefas cotidianas, a maioria contribui quando não está em crise, porém com suas limitações; os relacionamentos familiares são permeados de sentimentos de dor e sofrimento atrelado a pena e dó. Conclui-se que a enfermagem tem o importante papel de orientar e apoiar a família em suas necessidades.

Palavras-chave: Saúde mental. Enfermagem psiquiátrica. Família. Desinstitucionalização.

\begin{abstract}
The general objective of this study was to unveil through a family viewpoint the participation of mental health patients in their family life. It was a qualitative approach study, conducted between March and May 2010. The 14 contributors belonged to 11 families of mental health patients, residing in the city of Maringá-PR. Thematic oral history was used as the data collection technique. The results demonstrated there is still difficulty with regard to family participation and decisions. With regard to daily chores, most patients contribute whenever they are not in crisis, but with limitations; family relationships are permeated with feelings of pain and suffering associated with pity and commiseration. It is concluded that Nursing plays an important role in the family, by guiding and supporting its needs.
\end{abstract}

Keywords: Mental health. Psychiatric Nursing. Family. Deinstitutionalization.

\section{Resumen}

El objetivo general de este estudio fue revelar en la óptica familiar la participación del portador de trastorno mental en la vida en familia. Investigación de abordaje cualitativo, realizada en el período de marzo a mayo de 2010. Los 14 colaboradores pertenecen a once familias de portadores de trastornos mentales residentes en el municipio de Maringá-Pr. Utilizó la historia oral temática como técnica de recogida de los datos. Para análisis de los datos se utilizó la técnica de análisis de contenido temático. Los resultados demuestran que en relación a la participación y decisiones en familia, aún hay una dificultad en este aspecto. Cuanto a la participación en las tareas cotidianas, la mayoría contribuye cuando no está en crisis, pero con sus limitaciones; las relaciones familiares son mediadas de sentimientos de dolor y sufrimiento junto con pena y compasión. Se concluye que la enfermería tiene papel importante junto a la familia para orientarla y apoyarla en sus necesidades.

Palabras-Clave: Salud mental. Enfermería Psiquiátrica. Familia. Desinstitucionalización.

\footnotetext{
Enfermeiro. Mestre em Enfermagem na UEM. Brasil. Professor Assistente do departamento de Enfermagem da UEM. Membro do Grupo de Estudos, Pesquisa e Assistência de Enfermagem em Saúde Mental e Família (GEPAESMF). Maringá - PR. Brasil. E-mail: adriano.enfermeiro@hotmail.com Enfermeira. Doutora em Filosofia da Enfermagem. Docente do PSE/UEM. Chefe do Departamento de Enfermagem (DEN). Chefe do Grupo de Estudos, Pesquisa e Assistência de Enfermagem em Saúde Mental e Família (GEPAESMF). Coordenadora do Projeto de Pesquisa Financiado pela Fundação Araucária do Paraná pelo Edital 14/2009: a história da família do portador de transtorno mental como subsídio para ações de enfermagem. Maringá - PR. Brasil. E-mail: angelicawaidman@hotmail.com
} 


\section{INTRODUÇÃO}

Com o processo de desinstitucionalização, o portador de transtorno mental deixou de ser atendido exclusivamente em hospitais psiquiátricos e passou a ter outras opções de tratamento. Ocorreu uma reconfiguração da atenção em saúde mental, com vários avanços obtidos neste processo, destacandose: 0 acesso aumentado à atenção em saúde mental; 0 fechamento de 16.000 leitos em hospitais psiquiátricos; a redução do número total de leitos dos hospitais psiquiátricos restantes; a desinstitucionalização de pessoas com longo histórico de internação psiquiátrica; a utilização de recursos financeiros nas ações hospitalares substituída pelo investimento nas ações extra-hospitalares; a implantação de ações de saúde mental na atenção básica; e o enfrentamento da questão da inclusão social pelo trabalho como desafio intersetorial. ${ }^{1}$

Uma das alternativas adotadas pelo Ministério da Saúde (MS) foi a implantação de Centros de Atenção Psicossocial (CAPS). Estes serviços, que no ano de 1998 eram 148 em todo o Brasil, em junho de 2010 perfaziam o total de 1.541, enquanto o número de leitos psiquiátricos do Sistema Único de Saúde (SUS), que em 2002 era de 51.393, reduziu-se para 35.426, distribuídos atualmente em 208 hospitais

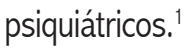

Diante destas ações, muitas das pessoas que ficavam em instituições fechadas passaram a não mais necessitar delas, e assim utilizam esse tempo no convívio diário com seus familiares e cuidadores, no domicílio.

Somando-se a esse processo de transição, o portador de transtorno mental busca efetivar a retomada do curso de sua vida exercendo sua cidadania, deixando assim de ser desprovido de seus direitos, diferentemente do que acontecia no paradigma anterior. Desta forma, com o decorrer do processo de desinstitucionalização, o portador de transtorno mental, até então excluído do convivio familiar, passou a ser (re)inserido nas rotinas de sua família, fazendo-se presente e, em algumas situações, tornando-se participativo. ${ }^{2}$

Não obstante, em decorrência dessas alterações efetuadas em vários setores, o trato com o portador de transtornos mentais no domicílio torna-se difícil. Isso se deve ao fato de que tanto o portador de transtorno quanto os seus familiares devem exercitar o convívio em busca de uma harmonia no lar, tornando este local um espaço para diálogo, discussão e oportunidades de expressão de formas diferentes de pensar ou se posicionar diante de alguma situação. Destarte, todos devem entender-se, respeitar-se e convergir para ações de consenso, de modo que o portador de transtorno possa ser respeitado e aceito com as limitações a ele impostas pela patologia.

Nesse momento de convivência e de adaptação ao domicílio, portadores e familiares precisam exercitar a habilidade de relacionamento, devendo estes últimos procurar conhecer o portador de transtorno mental na sua singularidade e avaliar sua experiência de sofrimento mediante o contato cotidiano na relação, valorizando aspectos importantes para sua vida, como, por exemplo, o esporte, o namoro, a família, o estudo, o trabalho e o lazer. ${ }^{3}$ É necessário ainda suprir outras dificuldades presentes no dia a dia em família, como a participação em atividades da casa e a divisão de tarefas no domicílio.

Durante as últimas décadas a constituição da sobrecarga em familiares tem sido usada para captar a experiência dos membros da família ao cuidarem de um familiar portador de transtorno mental. ${ }^{4}$ Essa sobrecarga gerada pelo convívio do portador com seus familiares/cuidadores pode representar em peso material, subjetivo, organizativo e social, surgindo, assim, problemas diversos, entre os quais os encargos econômicos, físicos e emocionais a que os familiares estão submetidos em decorrência desse convívio. ${ }^{5}$ A presença de sobrecarga é independente do diagnóstico da doença ${ }^{6} \mathrm{e}$ a experiência de conviver com o portador de transtorno mental resulta em um cotidiano conturbado.

Assim, deve-se procurar que o portador retorne para casa e considerar as condições e habilidades dele e dos familiares para essa vivência, caso contrário ela pode se tornar negativa. ${ }^{7}$ É notório que existem dificuldades diversas que contribuem para conturbar a participação do portador de transtorno mental no contexto da família, principalmente a de aceitação dele, devido ao seu comportamento gerado pela patologia.

Este panorama é agravado pela concepção, que ainda hoje permeia o imaginário da população, de que o portador de transtorno mental é perigoso e violento, reforçando o rótulo do estigma e preconceito contra ele.?

Há muito a ser trabalhado nos níveis assistencial, cultural, político, econômico e conceitual para se desmitificar o estigma da doença mental e, acima de tudo, garantir o direito de cidadania a essas pessoas para que possam viver melhor no mundo. ${ }^{8}$ Neste sentido, o presente estudo objetivou revelar, na ótica do familiar, a participação do portador de transtorno mental na vida em família.

\section{METODOLOGIA}

0 estudo consiste em pesquisa de abordagem qualitativa em que se utilizou como técnica de coleta de dados a História Oral Temática. Entende-se História Oral como uma prática de apreensão de narrativas destinada a recolher testemunhos, promover análises de processos sociais do presente e facilitar o conhecimento do meio imediato. ${ }^{9}$ Ela é temática porque a existência de um foco central justifica o ato da entrevista, recorta e conduz a possíveis objetividades. ${ }^{9}$ A História Oral difere de simples entrevistas, pois os procedimentos que a determinam não se restringem ao ato de apreensão das entrevistas, ressaltando-se todo o enquadramento em etapas previstas no projeto. $^{9}$

Este estudo foi realizado com 14 colaboradores, familiares de portadores de transtornos mentais membros de 
11 famílias que residem no município de Maringá e cujo membro portador teve passagem pela Emergência Psiquiátrica (EP) do Hospital Municipal de Maringá (HMM) no ano de 2008.

A coleta de dados ocorreu no período de março a maio de 2010. As histórias orais foram gravadas, transcritas na íntegra e posteriormente devolvidas aos colaboradores para que estes, após a leitura, complementassem-na até que constituíssem a representação real e fidedigna do ocorrido. ${ }^{9}$ Após a aprovação da história pelos colaboradores, analisaramse os dados por meio da Análise Temática de Conteúdo. ${ }^{10}$

A análise de conteúdo é um conjunto de técnicas de análise das comunicações que utiliza procedimentos sistemáticos e objetivos de descrição do conteúdo das mensagens, tem como finalidade a inferência de conhecimentos relativos às condições de produção ou recepção e recorre a indicadores, quantitativos ou não. ${ }^{10}$

A inferência é um processo de deduzir de maneira lógica caracterizado como a fase intermediária do processo no qual ocorre a passagem explícita e controlada dos dados das fases de descrição para a de interpretação ${ }^{10}$; não é, portanto, uma simples leitura, mas o realçar de um sentido que se encontra em segundo plano, buscando-se outros significados além do expresso. ${ }^{10}$ Assim, procura conhecer aquilo que está por trás das palavras sobre as quais se debruça. ${ }^{10}$

As diferentes fases da análise de conteúdo organizamse em torno de três polos cronológicos: a pré-análise: a exploração do material, o tratamento dos resultados e a inferência e interpretação. ${ }^{10}$

A pré-análise é a fase de organização dos documentos, isto é, aquela em que ocorreram a leitura flutuante, a escolha dos depoimentos, a formulação de hipóteses, a escolha dos índices e a elaboração de indicadores para fundamentar a interpretação. A fase de exploração do material é a que se segue à codificação do conteúdo dos discursos em unidades de registro, as quais são organizadas em categorias. A fase de tratamento dos resultados compreende a inferência e a interpretação. Neste estudo, realizaram-se inferências sobre os aspectos evidenciados pelos discursos quanto à significação da própria mensagem em si ou pelo que se escondia por detrás das falas; e na interpretação levou-se em conta o que se escondia sob a aparente realidade e o que significava verdadeiramente, em profundidade, 0 discurso enunciado. ${ }^{10}$

0 estudo respeitou os preceitos éticos e foi aprovado pelo Comitê Permanente de Ética em Pesquisa com Seres Humanos da Universidade Estadual de Maringá (Parecer N. ${ }^{\circ}$ 509/2009). Os colaboradores foram informados dos objetivos do estudo, do tipo de participação desejado e quanto à livre opção em participar e desistir desta participação a qualquer momento. Todos os colaboradores (familiares/cuidadores) assinaram o Termo de Consentimento Livre e Esclarecido e realizaram a validação do conteúdo das entrevistas. Para resguardar a identificação dos colaboradores atribuímos-lhes codinomes de flores.
Com a finalidade de contextualizar o portador de transtorno mental em relação ao colaborador deste estudo, podemos assim caracterizar os 14 colaboradores/11 famílias: Colaborador 1, Amarílis (esposa); Colaborador 2, Begônia (portador); Colaborador 3, Cravo 1 (pai); Colaborador 4, Cravo 2 (mãe); Colaborador 5, Dália 1 (mãe); Colaborador 6, Gérbera 1 (mãe); Colaborador 7, Gérbera 2 (irmã); Colaborador 8, Hortênsia (marido); Colaborador 9, Jasmim (marido); Colaborador 10, Lótus (irmã); Colaborador 11, Petúnia 1 (irmã); Colaborador 12, Petúnia 2 (irmã); Colaborador 13, Rosa (esposa); Colaborador 14, Violeta (mãe).

Ressalta-se que sempre que o portador esteve presente no domicílio durante a realização das entrevistas foi-lhe permitida a participação, se ele a desejasse. Após leituras exaustivas dos dados coletados e a utilização do método proposto, estes foram sistematizados, emergindo categorias temáticas.

\section{RESULTADOS E DISCUSSÃO}

\section{Opinião, escuta e respeito nas decisões em família}

Aqui estão dispostos os depoimentos dos colaboradores no que se refere à participação ativa do portador de transtorno mental nas decisões rotineiras, conversas, diálogos e assuntos de família vivenciados no seu cotidiano.

Segundo as informações dos colaboradores, a atitude mais comum dos portadores de transtorno mental, quando estão envolvidos em alguma questão no domicílio, é a de não emitir nenhuma opinião. Geralmente apenas escutam sem se expressar ou posicionar-se diante das situações.

[...] se a gente fosse conversar, ela preferia ficar igual uma coruja, só escutando, dificilmente dava um palpite "acho que é assim ou não", ela escuta. Mesmo se fosse pra brigar com ela, não respondia. Se fosse pra decidir alguma coisa, dificilmente ela dava uma opinião. Ela é tranquila até demais, [...] qualquer coisa somos eu e a mãe dela quem tínhamos que resolver. Resolver tudo! [...] pra fazer as coisas ela não estava muito aí, não. [...] Fazer ou não fazer, pra ela é uma coisa só, era normal, não estava nem aí, não [...] (Cravo 2).

[...] A gente tenta ao máximo incluir ela. Nas reuniões de família muita gente vai pra lá, mas mesmo assim ela se isola. Se a gente estiver em um grupo você não escuta ela falando nada. [...] pra você conversar com ela tem que estar puxando assunto e nem sempre você obtém resposta. Acaba sendo uma conversa bem unilateral. Você tenta conversar, mas não se vê o interesse do outro lado. A gente não sabe até que ponto é da doença, até 
que ponto é da personalidade dela ou da vontade. É bem complicado (Lótus).

Observa-se que o portador de transtorno mental não exerce seu direito de participar das atividades em família. Isso pode acontecer por várias razões, como: 1) as características da doença, o comprometimento afetivo, a dificuldade de comunicação, alterações no pensamento e na percepção e outras; 2) medo de se expor e não ser compreendido; 3) comodismo ou a concepção preconceituosa que trazem consigo de que não têm direito a se expressar, reflexo do modelo da internação hospitalar psiquiátrica, tradicionalmente enraizado em nossa cultura.

Por outro lado, ocorrem situações de castração do direito do portador de transtorno mental por parte da família, a qual, em determinadas circunstâncias, ignora as opiniões de seu familiar, impondo-lhe as decisões dos demais membros, e, em outras, simplesmente não dá valor ao que ele expressa, pensa ou deseja, justificando para si mesma que essa expressão seria decorrente da sintomatologia da doença, ou seja, fruto de alterações do pensamento ou da percepção.

[...] Não, ele não participa! Quem toma as decisões sou eu mesma. Tem vez que não adianta, ele quer as coisas erradas, mas se eu e os meninos vemos, a gente faz o que é certo, não importando se ele quer o errado (Rosa).

[...] acho que não tenho mais a mesma participação nas decisões de família. Eu acho que eles ainda têm um pouco de receio comigo por isso. Por ser uma família do interior, uma família tradicional, devem ter um pouco de receio ainda das minhas decisões, das minhas opiniões. [...] qualquer tipo de decisão que vai tomar lá em casa, se vai comprar alguma coisa ou não, eu não participo. Deve ser por eu ter passado por isso tudo, do transtorno mental (Begônia).

Apesar das mudanças em andamento, ainda prevalece a ideia de que o portador de transtorno mental não tem discernimento para tomar decisões e dar opiniões.

Begônia, que é portadora de transtorno mental, expressa com pesar e sofrimento a sua não participação na vida familiar no tocante às decisões. Em decorrência da internação psiquiátrica traz consigo o rótulo de incapaz de tomar decisões e de dar opiniões sobre questões familiares. Mesmo estando no domicílio, continua atrelada aos grilhões da institucionalização, do estigma e do preconceito dos séculos XIX e XX que excluíam, segregavam e aniquilavam o portador de transtorno mental, desvalorizando-o como ser humano e cidadão. Esta forma de pensar dos familiares e da comunidade em geral é característica do modelo asilar, em que o portador de transtorno mental é proibido de se expressar, e, quando se expressa, o faz de forma limitada e controlada pela instituição. ${ }^{11}$

As colaboradoras das famílias Amarílis, Dália e Gérbera falam da participação de seus familiares portadores de transtorno mental cada uma com sua peculiaridade.

Participa se a gente chamar ele para vir, se não, não. Mas tem vez que ele quer falar mais alto que a gente. Às vezes ele vence a gente pelo cansaço, de tanto a gente bater boca. A gente não aguenta porque ele fala demais, aí a gente fica quieto $e$ deixa ele falar. Pelo cansaço ele vence a gente. Eu nunca agredi ele e nem nada, mas ele me vence pelo cansaço de bater boca. Aía gente larga ele de mão, é ele pra lá e a gente pra cá e fica de boa (Gérbera 2).

Pela opinião de Gérbera 2, percebe-se que a família tem dificuldades em lidar com o familiar, e também que há uma ambiguidade em suas atitudes. Ao mesmo tempo em que deseja a participação dele, seu comportamento descontrolado e manipulador interfere na dinâmica familiar e, sem saber como lidar com a situação, usa a expressão "larga de mão e deixa pra lá". Isso demonstra também certo cansaço da família na convivência e até desesperança em relação à inclusão do portador de transtorno mental na vida social, seja ela em âmbito privado ou não.

Acho que ele tem necessidade de amizade, de conversa. Quando alguém da família chega, a gente percebe que ele quer falar. Éouvido, mas de repente, quer interromper e se não é ouvido na hora, dá meia-volta e vai pro quarto. É assim [...] confunde muito as coisas, então o que a gente tem que falar aqui, a gente fala normal. Não tem o que esconder [...] Ele participa, numa forma assim meio que limitada, porque ele é uma pessoa um pouco limitada. Com certeza ele é limitado em muitas coisas, só que está começando a entrar pro mundo (Dália 1).

A gente discute tudo normal, mas se for alguma coisa que tem que raciocinar muito, aíjá não dá. $E$ ́ isso. Antes ele participava mais, falava mais. Hoje ele já não fala mais como falava. Já é mais quieto. Se você conversar ele conversa, agora, ele puxar conversa e ficar conversado, ele não puxa mais. Está mais quieto, mais fechado, introvertido (Amarilis).

Dália e Amarílis relatam que há uma limitação de seus familiares com transtorno mental quanto ao raciocínio, e Dália deixa implícito que esta limitação é geral. Algumas doenças 
mentais têm sintomas que promovem embotamento afetivo e isolamento social, e alguns tipos de delírio fazem com que a pessoa se sinta perseguida, desprotegida, com medo, acuada; as alucinações provocam nela reações diversas, como retraimento, hiperatividade, angústia, etc., e muitas vezes as famílias, não conseguindo entender estes comportamentos, associam-nos a má conduta, falta de habilidade ou incapacidade para desenvolver certas atividades. Por isso, muitas vezes o portador de transtorno mental é estigmatizado pelos membros da família e pela comunidade como incapaz, inabilitado, incompetente e antissocial.

Neste sentido, os serviços extra-hospitalares têm como uma de suas funções oferecer atendimento às famílias para esclarecer a sintomatologia da doença e torná-las aliadas e colaboradoras no tratamento, mantendo o portador desinstitucionalizado ${ }^{12}$ para que assim possa ser compreendido em sua singularidade.

Destarte, é fundamental garantir ao portador de transtorno mental o direito de ir e vir, de ser ouvido, de opinar, de ser tratado com dignidade e respeito. Ele deve ser respeitado em seu desejo de participar da vida em família, o que se reflete em estímulos que o motivam a expressar-se, efetivando-se, assim, sua inclusão no contexto familiar.

Na família Hortênsia, a inclusão do portador é compulsória, ou seja, é-lhe imposta sem o direito de não concordar em participar, visto que, para o colaborador, é primordial sua participação nas atividades a serem desempenhadas ou nas decisões a serem tomadas, não importando as condições em que ele se encontre.

\section{[...] Não tem como poupar. [...] Participa porque às vezes tem as meninas aíné. Acontece alguma coisa e eu sou homem e ela é mulher, às vezes tem coisa que ela quem tem que me ajudar a decidir, eu sozinho não consigo. [...] Eu preciso da ajuda dela. Ela tem que participar dos fatos, sejam eles bons ou sejam ruins (Hortênsia).}

A nosso ver, o ser humano tem o direito de escolher o que fazer - por exemplo, se não está bem, pode ficar quieto, sozinho, em paz. Isso também ocorre com alguns portadores de transtorno mental, porém o colaborador da família Hortência mostra que não leva em consideração as condições físicas e psicológicas da esposa ao exigir sua participação nas atividades cotidianas. Essa atitude aponta falta de liberdade de escolha e da percepção das condições em que o outro se encontra, demonstrando que a liberdade do portador de transtorno mental nesta família é castrada, as coisas Ihe são impostas.

0 cuidado da família ao portador de transtorno mental geralmente fica por conta da mulher. Esta ainda pode acumular outros encargos, como a limpeza da casa, a alimentação do grupo familiar e o cuidado a outros membros da família. A presença da mulher como principal fonte de cuidados ao portador de transtorno mental já foi apontada pela literatura. ${ }^{13}$ Presa à função de cuidadora, ela não se permite sequer adoecer, pois se encontra na posição de responsável pelos cuidados à família. Essa centralidade conferida à mulher enquanto responsável pelos cuidados à família traz-lhe consequências, por exemplo, no tocante a assumir tarefas mais pesadas e exigentes por mais tempo e com alto custo em termos de saúde e qualidade de vida, de acesso a emprego, de desenvolvimento profissional, de relações sociais e de disponibilidade do próprio tempo, além de repercussões econômicas. ${ }^{14}$

\section{Participação no cotidiano: executando as tarefas familiares}

Em nossa vivência profissional de pesquisador, percebemos que é relevante buscar a inclusão do portador em seu domicílio. Uma alternativa é compartilhar as tarefas e responsabilidades do lar com seus familiares, mostrar-se útil e colaborativo, pois assim se torna possível promover um ambiente propício para se estabelecer um relacionamento harmonioso e com menor ou nenhuma sobrecarga.

\section{[...] É, nós dividíamos o serviço. Não era muita coisa, mas ela ajudava. [...] ela também trabalha, mas ela ajudava. Eu falava "vou fazer tal coisa e você faz outra", ela fazia; não reclamava. Eu lavava roupa e ela passava. Eu chegava primeiro que ela e ia fazer a janta. A louça da janta ela que lavava. Então, assim, a gente dividia o serviço da casa. Era assim que a gente fazia. Ela ajudou bem no último um ano e pouco que morou com a gente. Agora ela está morando com as crianças dela em outra casa (Cravo 2).}

Na fala de Cravo 2 é possível perceber que o portador de transtorno mental compartilha das tarefas domésticas e está inserido no mercado de trabalho, o que mostra que nessa família ele está adaptado à nova estratégia de saúde mental, reinserindo-se socialmente. Não obstante, ocorrem situações em que, mesmo a colaboração sendo solicitada, essas tarefas não são realizadas, e isso acarreta acúmulo de tarefas e funções para os familiares, resultando em sobrecarga para estes, conforme relato de Dália e Rosa.

[...] fiz o almoço e falei "filho você lava a louça porque eu vou descansar um pouco", ele tinha ido ao curso dele e eu disse "lava a loucinha porque eu vou descansar um pouco, depois a gente vai na fábrica. Depois nós vamos na missa, hoje é quartafeira." Eu propus pra ele. Ele disse "não vou lavar louça, não vou na fábrica e não vou na feira". Eu falei "tudo bem, você quem sabe". Ele estava cansado, eu senti. Daí ele deitou e dormiu e deixei ele tranquilo. Eu me organizei, ele levantou, deu 
uma olhada, viu que eu tinha lavado a louça e tranquilizou. Quando eram umas quatro e meia falei "vamos pra fábrica?" ele falou "vamos", pegamos as coisas e fomos [...] Tem horas que é não, não e não, de repente ele se arrepende e volta. "Você limpa a cozinha hoje pra mim", falo pra ele, daí ele fala "não vou". Daqui a pouco ele dá uma volta, vem aqui e fala que ele não quer ser pressionado (Dália).

[...] não faz nada! \{ao relatar sobre o auxílio do marido nas tarefas de casa\} (Rosa).

Nestes relatos é possível observar dois aspectos de sobrecarga: 1) aspecto objetivo, que compreende dificuldades concretas e observáveis causadas pelo comportamento do portador, as quais se refletem em consequências negativas do transtorno mental na família, como, por exemplo, não realizar as atividades da casa; 2) aspecto subjetivo, que se refere à percepção ou avaliação pessoal do familiar/cuidador sobre a situação, envolvendo ainda suas reações emocionais e seus sentimentos em relação à presença do transtorno mental na família. ${ }^{5,7,15}$ Os aspectos subjetivos vinculam-se à relação conturbada, que acarreta sentimentos negativos relacionados à manipulação do ambiente pelo portador. Evidencia-se sobrecarga emocional na face de Dália, quando ela fala.

Quando o familiar não tem a ajuda do portador na realização de atividades / tarefas no domicílio, ele se acostuma com a situação; mas a situação se modifica substancialmente quando o portador já realizava essas funções e, em decorrência de outros motivos, deixa de realizá-las. Para as famílias Gérbera e Violeta, o motivo de ele não mais realizálas é ter assumido um trabalho na sociedade.

Quando ele não estava trabalhando e a irmã estava, ele ajudava em casa, por exemplo, quando ficou um ano parado, lavava a louça. Era serviço dele. [...] só que quando está trabalhando, ele chega tarde, não vai fazer nada mesmo. Só fazia porque a irmã estava trabalhando e o irmão estudando. Aí ele era obrigado a ajudar porque não tinha outro pra fazer (Gérbera 1).

[...] Mudou muita coisa porque ela sempre foi uma mãe zelosa e uma dona de casa super zelosa. Era linda a casa dela, era um brilho, bem cuidada. Sabe, as pessoas, o marido, tinham o maior prazer de chegar em casa, porque era tudo muito bem cuidado. A comida muito bem feita e na hora. [...] Ela começou a deixar de fazer o serviço. Com o passar do tempo, ela começou a querer trabalhar fora. Ela achava que tinha que trabalhar fora e que não tinha obrigação nenhuma de ficar dentro de casa. Uma pessoa que era totalmente dedicada, de repente, demonstrar essa vontade de trabalhar fora, sendo que ela não tinha condições porque ela não dava conta nem de fazer o serviço dela na casa (Violeta).

A experiência de ter um membro da família sofrendo um transtorno mental, seja qual for a forma como ele se manifesta, mobiliza a família como um todo no seu dia a dia, sendo difícil necessitar desse familiar e ele não poder colaborar no cotidiano. ${ }^{16}$

A nosso ver, é importante que o portador de transtorno mental, caso se sinta bem, colabore na realização das tarefas do lar, e que apenas no momento em que estiver indisposto ou não se sentir bem deixe de fazer essas tarefas, sem que haja pressões ou cobranças exageradas, pois estas podem agravar o quadro ou o clima de tensão familiar. Para a família, esse compartilhar de responsabilidades é fator imprescindível para estabelecer relacionamento estável, digno e compreensivo entre a família e o portador.

[...] Quando ela está bem, ela levanta, faz o serviço de casa, que tem que fazer certinho, não precisa ninguém falar nada, mas quando não está [...] ela fica igual um bicho acuado. Não sai de dentro de casa, às vezes ela não sai nem do próprio quarto, às vezes ela fica o dia inteiro dentro do quarto [...] Às vezes, tem dia que ela não está bem, que ela não faz nada dentro de casa. Aí eu já cobro dela. Aí já fala que não está boa, daí eu ... na hora, de momento, eu fico nervoso, estressado, mas depois eu já acalmo também e "ah! Tudo bem! Não deu pra fazer, não deu, deixa". [...] Eu não ligo pra qualquer tipo de coisa, mas eu cobro. Eu falo pra ela "ó porque você não fez isso ou aquilo?" e ela "ah eu não estava muito bem". Na hora eu fico... Depois eu penso: o serviço nunca acaba e a gente acaba, né (Hortênsia).

Fica querendo ajudar, a lavar uma louça, varrer a casa, o quintal. Quando ele está bem ele faz, ajuda. Agora, quando ele não está bem, não ajuda com nada (Petúnia 1).

É perceptível nos depoimentos que a família precisa ser preparada para compreender a doença, suas fases e aspectos, a fim de evitar conflitos. Também é importante respeitar as limitações do indivíduo que está em crise e compreender a sua singularidade. Se isto não acontecer, a convivência se tornará difícil e isto interferirá no processo de ressocialização e reinserção social. 


\section{A participação do portador de transtorno mental nas relações em família: um destaque para os sentimentos}

A análise revelou depoimentos impregnados de sentimentos e emoções presentes na rotina diária, derivados de relações nem sempre harmoniosas. Em seu convívio, os familiares e portadores de transtornos mentais apresentam condições variadas, como dificuldade em lidar com as situações de crise vividas e com os conflitos familiares emergentes, a culpa e o pessimismo por não conseguirem ver uma saída para os problemas enfrentados, o isolamento social a que ficam sujeitos, as dificuldades materiais da vida cotidiana, a complexidade do relacionamento com o familiar doente, expectativas frustradas de cura e desconhecimento da doença. ${ }^{17}$

0 colaborador expressa o desejo de ver a união dos membros da família em relação ao transtorno mental, bem como a existência de compreensão, aceitação, colaboração, respeito e amizade entre eles, condições que efetivam literalmente o sentido de família na busca por superar esses problemas.

A preocupação de obter a união dos membros da família para um futuro em que este cuidador não esteja mais entre eles é também sinônimo de sobrecarga ao familiar. ${ }^{6}$ Eles sabem que, se não houver uma figura de referência, os conflitos podem se intensificar e, diante disso, tentam unir os membros da família para que, juntos, busquem soluções para os seus problemas.

[...] ele é bonzinho com os outros e pra mim não. Eu quem aguento tudo. [...] Eu queria assim, a única coisa que eu tenho vontade é que ele melhorasse. Que ele ficasse igual os outros dentro de casa. Como se fala, mais amigo (Gérbera 1).

\section{[...] Eu estou tentando ver se de vez em quando a irmã dá uma puxadinha assim, pro lado dele, defendendo e apoiando ele. São umas coisas assim, (desentendimentos por coisas pequenas), no final da vida não sei como é que vai ser, então eles precisam se entender! É o que mais quero (que a famillia fique unida) (Dália).}

Ressalta-se a presença marcante de sofrimento nos depoimentos emitidos pelos colaboradores. Este sofrimento decorre das várias dificuldades impostas pela doença. Uma consequência desse sofrimento é o adoecimento dos familiares, na forma principal de sobrecarga, o que é corroborado pela literatura. ${ }^{7,18}$

$[\ldots]$ sofrimento[...], a gente vê ele como ser humano, não como uma pessoa doente. Você sabe que tem a doença ali, mas que do outro lado tem o ser humano. Quer abraçar as duas e não pode. Foram momentos muito difíceis que nós passamos dentro dos hospitais, então veio na minha lembrança. [...] a gente quer ter uma esperança de mudança de vida \{chora, respira fundo e continua\}, é difícil. Mas é assim, eu me emociono mais humanamente. Não queria ver ele sofrer e quando você lembra dos momentos dificeis que passou, que foram muito sofridos, então, seilá, a gente se emociona \{chora novamente\} (Petúnia 2).

Diante do sofrimento enfrentado pelo familiar e pelo portador, sempre se faz presente a esperança de mudança de vida ou de melhora, mesmo no contexto desfavorável, ${ }^{7}$ de frequentes entradas e saídas do hospital, em que a família, aos poucos, perde suas forças e é levada a fortes sentimentos de emoção, como se observa no relato de Petúnia 2. Diante dessa situação é necessário que o familiar saiba reconhecer seus limites para ele também não ficar doente. Ele deve fazer 0 possível diante de situações adversas, mas não deve se sobrecarregar na resolução destes problemas.

A partir daí surge uma nova dinâmica no modo de ser da família, e ela adquire forças para aceitar e ajudar o membro portador, aprendendo a conviver com a doença. ${ }^{16}$

[...] Eu estava ficando doente também de tanto sofrimento. Estava uma pessoa descontrolada, só chorava de ver minha filha tão ruim, tão doente, doente da cabeça. [...] Foi uma vida muito corrida, foi muito sofrimento, muito desgaste físico, tive desgaste de tanto viajar pra lá e pra cá todo mês, às vezes acontecia de ter que ir duas vezes ao mês. Acabava de chegar aqui e tinha que voltar. [...]Porque esse medicamento mata (que a filha fazia uso para emagrecer), deixa primeiro com transtorno bipolar, deixa a pessoa completamente louca, vai matando a família e a família não sabe por quê. Pra descobrirtem que ser uma mãe mesmo (Violeta).

As famílias precisam de amparo e apoio, e é neste sentido que os profissionais de saúde, especialmente os da enfermagem, devem aproximar-se delas, com a finalidade de compartilhar maneiras de enfrentar os problemas e construir uma convivência saudável, e principalmente, precisam estar preparados para informar a família e favorecer as transformações na sua forma de lidar com o doente, ${ }^{5}$ mediante a educação em saúde.

Percebe-se também nos depoimentos o esgotamento físico e mental das famílias, e certa ambiguidade de sentimentos, tanto que os familiares, não conseguindo expressar-se com palavras, choram, ficam trêmulos e com olhos lacrimejantes; eles perdem a voz e mudam a expressão da face, em uma linguagem corporal que expressa toda a dor e sofrimento que somente quem convive com esta realidade é 
capaz de descrever com propriedade, não somente com palavras, mas com a linguagem verbal e não verbal.

Também se nota a presença de sentimentos de pena ou dó da situação em que o portador se encontra, sentimentos que em nada auxiliam na relação que se estabelece entre 0 portador e o familiar - ao contrário, só fazem aumentar 0 sofrimento destes familiares, ao invés de beneficiar a convivência. Neste sentido, ao se assumir o cuidado do doente, podem emergir sentimentos e emoções latentes, provocando desequilíbrio e sofrimento.

[...] Porque até então lá ninguém conseguia internar ela, uma porque ela não queria, não aceitava, outra o marido tinha dó e achava que ia ser pior se ela fosse internada (Violeta).

[...] meu filho veio e quando ele chegou no portão atiraram nas costas dele. Ele foi assassinado [...], desse dia em diante o meu marido entrou numa depressão, ele ficou psicótico e assim até hoje ele chora todo dia. [...] A foto do meu filho está ali, \{mostra a foto na estante\}, ele olha e chora, quero guardar, ele não deixa. Eu tenho que ir ao cemitério todo final de semana, aí a gente vai lá, reza o terço e parece que ele se sente mais leve. Eu falo assim: "que dói, dói, é meu filho também". Sinto saudade, mas só de falar que a gente sente saudade ele já começa a chorar, mas a gente tem que se conformar, a vida tem que continuar. [...] A familia morre de dó dele, do jeito que ele está. A minha filha, essa semana, me disse: 'mãe eu olho pro pai e me dá tanta dó dele, ele se acabou de uma vez'. [...] só que não conversa, não sorri mais. Então mudou tudo. E o problema agora está sendo o serviço. Porque ele étrabalhador, ébom, mas não está dando mais. Os vizinhos sabem como é que ele está, comigo conversam normal, vêm e falam pra mim porque as pessoas veem que ele está diferente, não está como era antes. Ele não saía na rua. Eu já estou vendo que as pessoas estão deixando de contratar ele por causa disso. Sabe, ele fica com o raciocínio lento. Gente, como está difícil! Do jeito que está, não dá! Ele vai falar alguma coisa e fica gaguejando né, olha, está um caos. [neste momento enche os olhos de lágrimas]. (Amarílis).

A dificuldade de se relacionar com os familiares, vizinhos e empregadores, o isolamento social e familiar ao ponto de nem sair à rua, as dificuldades em conseguir emprego para suprir a falta de recursos financeiros no domicílio, as alterações decorrentes de efeitos colaterais dos medicamentos sobre 0 portador - como a sonolência e a lentidão do raciocínio -, o fato de este não poder ajudar nas tarefas da casa, tudo isso modifica a rotina da família e provoca em todos sofrimento e sensação de impotência.

Diante de um quadro de sofrimento psíquico, o familiar precisa estar preparado para enfrentar as várias situações que podem surgir em decorrência do transtorno. A dificuldade em demonstrar afeto, a falta de diálogo e atitudes impulsivas são reações comumente apresentadas por portadores de transtornos mentais. 0 medo e a preocupação vivenciados pelos familiares são decorrentes destes comportamentos explosivos e também figuram neste contexto. Como consequência da não compreensão da doença e de seus efeitos ocorre 0 afastamento de amigos e familiares, o que perpetua a cultura de estigma e preconceito em relação à pessoa acometida de transtorno mental. Esses resultados são corroborados pela literatura. ${ }^{7}$

[...] Ela não tem muita graça com os filhos. Assim de brincar, de agradar. Ela não tem isso daí e qualquer coisa ela já esbraveja com eles e não tem aquele negócio de conversar. Ela gosta deles, mas, igual ela fala, se por causa dos filhos dela tiver que matar, brigar, ela faz. Só que é aquele negócio, não demonstra que gosta. [...] agora que ela mudou lá pra casa nova dela, desses pouquinhos dias, parece que ela está agradando mais eles do que quando estava aqui em casa porque quando estava aqui em casa, qualquer coisa "olha, não sei o quê, vivia reclamando das crianças [...]" (Cravo 1).

[...] A gente vive com medo, com preocupação. Quando você deita na cama você está pensando o que pode estar acontecendo lá. [...] Olha, a gente é uma familia de 10 irmãos, mas esse problema dele foi o que acabou com a nossa vida. [...] Às vezes você tem que fugir porque ele ficou lá falando aquele monte de coisas (delírios). O médico falou que você não pode dar lado pra confusão da mente dele. (Petúnia 2). É assim, com ele eu já lido assim; tenho medo! Já levei muito susto, então eu fico desse jeito. Já saí de lá corrida várias vezes. [...] Tenho receio da minha mãe com ele, pois me peitou e eu parei de frente pra ele. (Petúnia 1).

[...] os parentes vinham em casa, ela cuidava de tudo. Todo mundo gostava de vir em casa. Depois disso \{surgimento do transtorno mental\}, até os parentes, se vêm aqui, não vêm mais com aquela alegria de ficar em casa [...] (Jasmim).

Para a família, vivenciar a realidade resultante da sintomatologia do transtorno mental em seus membros produz um grande sofrimento. Diante dessa situação, buscam-se formas de aliviá-la. Dificilmente as famílias buscam um apoio especializado para obter esse resultado, procuram dialogar ou 
informar-se sobre a patologia. Uma das formas mais utilizadas para aliviar esse sofrimento é a tentativa de proteger-se, o que se dá principalmente por meio do afastamento/isolamento social. Familiares deixam de frequentar a casa do portador ou eventos realizados nela. Por outro lado, os que residem com o portador deixam de sair de casa e não exercitam o convívio social, com receio de alguma atitude que venha a causar-lhes constrangimento. Aspecto relevante relacionado à geração de sofrimento é a falta de contribuição financeira do portador no domicílio.

Corrobora nossos resultados a afirmação de que as famílias que convivem com o transtorno mental mostram preocupação, impotência e medo diante do comportamento inadequado e imprevisível e da inconstância de humor do portador de transtorno mental, o qual por vezes toma atitudes que causam certa perplexidade. ${ }^{18}$ Também é comum 0 afastamento de membros da família, os quais, em vez de tentar entender a doença e agir no sentido de que seu familiar a supere, dele se afastam como meio de se proteger contra os desafios da doença. Os dados aqui encontrados são semelhantes ao de um estudo ${ }^{7}$ que mostrou o afastamento dos familiares como atrelado a atitudes de preconceito e estigma.

Assim, a nosso ver, é imprescindível orientar os envolvidos no contexto domiciliar decorrente da convivência do portador com o familiar cuidador, no sentido de que ambos saibam enfrentar e gerir a gama de sentimentos gerados neste processo, inclusive para que os demais membros da família reconheçam a importância de seu apoio ao familiar que sofre com o transtorno mental e possam promover estímulos positivos.

\section{CONSIDERAÇÕES FINAIS}

A metodologia utilizada na pesquisa permitiu recriar a realidade vivenciada pelo colaborador, refletindo-se na reconstituição fiel da história contada por eles. Observou-se que os colaboradores desta pesquisa estão carentes de informaç̃̃es sobre o transtorno mental. Com o recebimento de orientações adequadas nos serviços de saúde mental, eles podem deixar de vivenciar dificuldades no relacionamento com o portador e passar a compreender que o comportamento dele decorre de sua doença. Essa lacuna pode ser suprida pela atuação do enfermeiro com orientações e acompanhamento direcionados a cada caso, tanto nos serviços especializados de saúde mental quanto no próprio ambiente domiciliar, em grupos de apoio ou em associações de familiares e portadores.

Percebemos que a participação do portador de transtorno mental no contexto e convívio de sua família ocorre de diferentes formas. Essa participação varia de família para família e se dá de forma mais adequada nas que permitem e estimulam a participação do portador, sem receio, estigma ou preconceito. 0 portador de transtorno mental pode demonstrar sua importância junto à família e conquistar seu respeito e apoio ao realizar pequenas tarefas familiares e domiciliares, deixando de sobrecarregar os demais.

Ao vivenciar as relações em família, destacam-se na rotina diária sentimentos e emoções, decorrentes principalmente das dificuldades impostas pela doença. Neste sentido, é necessário que o familiar, especialmente o cuidador, respeite seus limites para que não fique doente também, por exemplo, entrando em depressão em virtude da sobrecarga financeira e de cuidados produzida pelo portador de transtorno mental. Deve-se ainda orientar a família no sentido de que ela possa compreender a patologia, para que atribulações e percalços não estejam presentes nos relacionamentos e, caso o estejam, tenham efeitos menores. Assim, concluímos que realizar educação em saúde é primordial para se efetivar a inclusão definitiva do portador na família e na sociedade como um todo.

\section{REFERÊNCIAS}

1.Ministério da Saúde (BR). Coordenação Geral de Saúde Mental, Álcool e Outras Drogas. Saúde Mental em Dados-7. [Informativo eletrônico]. 2010 junho; [citado 2011 out] ano 5 (ed esp (7): 25. Disponível em: www.saude.gov.bre www.saude.gov.br/bvs/saudemental

2. Brischiliari A. A participação do portador de transtorno mental no contexto familiar [dissertação]. Maringá: Departamento de Enfermagem, Universidade Estadual de Maringá; 2010.

3. Loyola CMD, Kirschbaum D, Rocha R, Rodrigues J. Cotidiano dos serviços: trabalhadores, usuários e familiares na produção do cuidado. In: Textos de apoio para a $4^{\text {a }}$ Conferência Nacional de Saúde Mental [on-line] 2010; [citado 2010 out 07]. Disponível em: http://portal.saude.gov.br/portal/ arquivos/pdf/cotidianoloyola.pdf.

4. Glanville DN, Dixon L. Caregiver burden, family treatment aproaches and service use in families of patients with schizophrenia. Isr J Psychiatry Relat Sci. 2005; 42(1): 15-22.

5. Souza RC, Scatena MCM. Produção de sentidos acerca da família que convive com o doente mental. Rev Latino-am Enfermagem. 2005 mar/ abril; 13 (2): 173-79.

6. Hadrys T, Adamowski T, Kiejna A. Mental disorder in Polish families: is a predictor of caregiver's burden? Soc Psychiatry Psychiatr Epidemiol. 2010. Mar; 23 [citado 2010 out 08]. Disponível em: http:// www.ncbi.nlm.nih.gov/pubmed/20309676.

7. Jorge MSB, Ramirez ARA, Lopes CHAF, Queiroz MVO, Bastos VB. Representações sociais das famílias e dos usuários sobre participação de pessoas com transtorno mental. Rev Esc Enferm USP. 2008; 42(1): $135-42$. 
8. Santos ACCF. Referencial de cuidar em enfermagem psiquiátrica: um processo de reflexão de um grupo de enfermeiras. Esc Anna Nery. 2009 jan/mar; 13(1): 51-5.

9. Meihy JCSB, Holanda F. História oral: como fazer, como pensar. São Paulo: Contexto; 2007.

10. Bardin, L. Análise de conteúdo. $3^{\text {a }}$ ed. Lisboa: Ed 70; 2008.

11. Castro AS, Furegato ARF, Santos, JLF. Características sociodemográficas e clínicas em reinternações psiquiátricas. Rev Latino-am Enfermagem. 2010 jul/ago; 18(4): 800-08.

12. Waidman MAP, Radovanovic CAT, Scardoelli MGC, Estevam MC, Pini JS, Brischiliari A. Estratégia de cuidado a familias de portadores de transtornos mentais: experiências de um grupo de pesquisa. Cienc Cuid Saude. 2009; 8 (supl 1): 97-103.

13. Pegoraro RF, Caldana RHL. Sofrimento psíquico em familiares de usuários de um Centro de Atenção Psicossocial (CAPS). Interface: comunic, saude, educ. 2008; 12 (25): 295-307.

14. Gutierrez DMD, Minayo MCS. Produção de conhecimento sobre cuidados da saúde no âmbito da família. Cienc Saude Colet. 2010 jun; 15 (supl 1): 1497-508.

15. Bandeira M, Barroso SM. Sobrecarga das famílias de pacientes psiquiátricos. J Bras Psiquiatr. 2005 jan/mar; 54(1): 34-46.

16. Navarini V, Hirdes A. A família do portador de transtorno mental: identificando recursos adaptativos. Texto \& Contexto Enferm. 2008 out/ dez; 17(4): 680-88.

17. Colvero LA, Ide CAC, Rolim MA. Família e doença mental: a difícil convivência com a diferença. Rev Esc Enferm USP. 2004; 38(2):197205.

18. Borba LO, Schwartz E, Kantorski LP. A sobrecarga da família que convive com a realidade do transtorno mental. Acta Paul. Enferm. 2008; 21(4): 588-94.

\section{NOTA}

aArtigo integrante da dissertação de mestrado intitulada "O portador de transtorno mental no contexto familiar: percepções da família", apresentado ao Programa de Pós-Graduação Mestrado em Enfermagem da Universidade Estadual de Maringá (PSE/UEM), em 2010, para obtenção do título de Mestre em Enfermagem. 